\title{
Mothers with COVID-19 and Their Newborn Infants: A Joint Position Statement on Shared Decision-Making
}

Joan Rikli, MBA, MSN, RN, Jerasimos Ballas, MD, MPH, Dionne Wllson, CAE, Kristy Love

The National Perinatal Association (NPA) is an interdisciplinary organization that strives to be a leading voice for perinatal care in the United States. Our diverse membership is comprised of healthcare providers, parents \& caregivers, educators, and service providers, all driven by their desire to give voice to and support babies and families at risk across the country.

Members of the NPA write a regular peer-reviewed column in Neonatology Today.

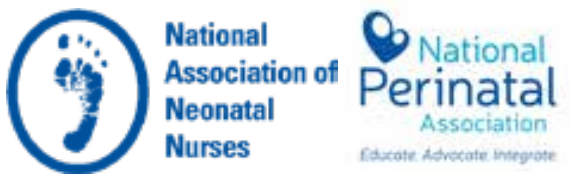

As the Covid-19 pandemic continues to shape all our lives, those who provide care to pregnant patients, their families, and newborns face a challenging task. We are entrusted with the responsibility of formulating new policies for childbirth and newborn care in the midst of a dynamic public health crisis. So how do you create evidence-based guidelines when the evidence is evolving?

Parents and providers get new data every day and the information we need to make informed decisions is ever-changing. This not only poses significant challenges in creating a safe environment for patients and first line healthcare workers, but also in maintaining the highest standards of ethical and compassionate care at such a potentially vulnerable time for both parents and newborns.

The National Perinatal Association (NPA) and National Association of Neonatal Nurses (NANN) recognize these unique challenges and offer guidance in creating a culture of shared decision-making when providers must deliver the newborn of a

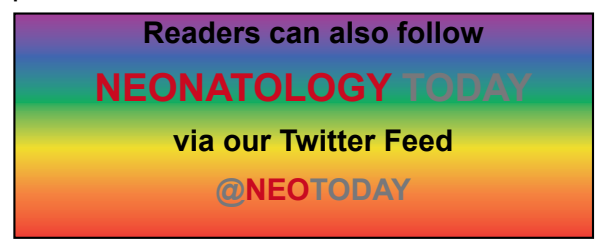

Covid-19+ mother or when the mother is a Patient Under Investigation (PUI).

Drawing from the multidisciplinary experience of our organizations, we have created a Joint Position Statement addressing the need to balance evidence-based practices for both infection control and protection of healthcare providers with the established benefit of newborn bonding and breastfeeding in the 4 th trimester.

With information changing rapidly as more data is collected, we acknowledge the potential for policy changes based on in- stitutional constraints and regional developments. However, any policy must start with the dignity of the patient at its core and aspire to do no harm as we all navigate these challenging and uncertain times.

Disclosure: The National Perinatal Association www.nationalperinatal.org is a $501 \mathrm{c} 3$ organization that provides education and advocacy around issues affecting the health of mothers, babies, and families.

\section{NT}

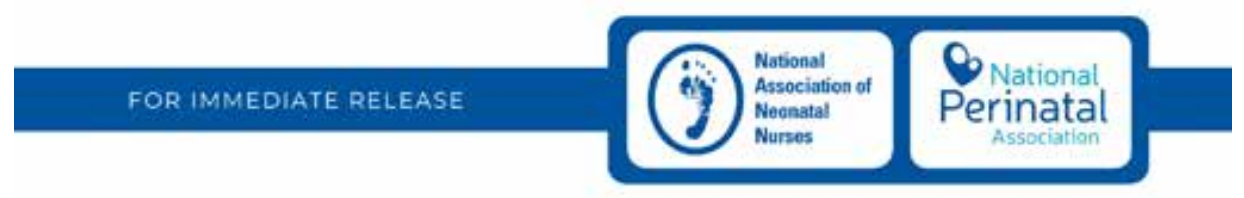

\section{Mothers with COVID-19 and Their Newborn Infants}

A Joint Position Statement on Shared Decision-Making

\begin{abstract}
Chicago, IL May 11
As the Covid-19 pandemic continues to shape all cur lives, those who provide care to pregnant patiens, their families, and newborns tace a challenging task. We are entrusted with the responsibility of formulating new policies for childbirth and newbom care in the midst of a dynamic public health crisis. So how do you create evidence based guidelines when the evidence is evolving?
\end{abstract}

Parents and providers get new data every day and the information we need to make intormed decisions is ever-changing. This not only poses signiticant challenges in creating a safe environment for patients and first line healthcare workers, but also in maintaining the highest standards of ethical and compassionate care at such a potentially vulnerable time for both parents and newborns.

\begin{abstract}
The National Perinatal Association (NPA) and National Association of Neonatal Nurses (NANN) recognize these unique challenges and offer guidance in creating a culture of shaved decision-making when providers must deliver the newboin of a COVID-19* mother or when the mother is a Pabent Under Investigation (PUI).
\end{abstract}

Drawing from the muitidisciplinary expenience of our organizations, we have created a Joint Postion Statenent addressing the need to balance evidence-based practices for both infection control and protection of healthcare providers with the established benefit of newborn bonding and breastleeding in the 4th trimester.

With information changing rapidly as more data is collected, we acknowledge the potential for policy changes based on institutional constraints and regional developments. However, any policy must start with the dignity of the patient at its core and aspire to do no harm as we all navigate these challenging and uncertain times.
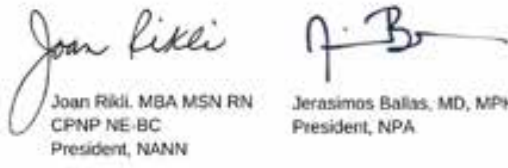
President, NPA

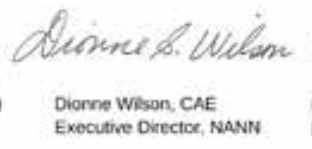

Kriaty Love Knsty Love Execubve Director, NPA 
Joint Position Statement

May 2020
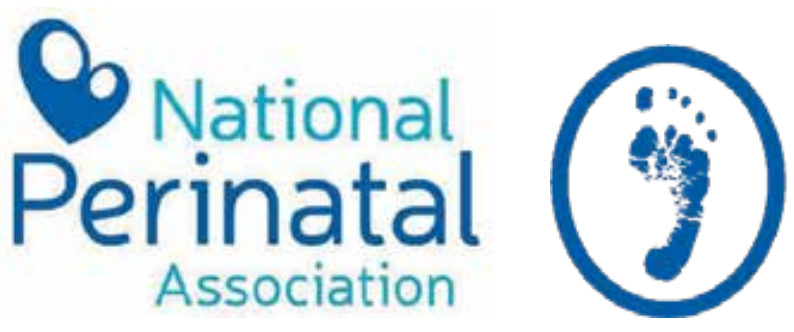

National Association of Neonatal Nurses

\section{Mothers with COVID-19 and Their Newborn Infants}

\section{Issue: Shared Decision Making}

The National Association of Neonatal Nurses (NANN) and the National Perinatal Association (NPA) fully support the incorporation of a shared-decision model between the mother and the clinical team to determine the best care for the mother-newborn dyad.

NANN and NPA encourage the ideal scenario, which is to keep mother and newborn together while respecting the unique challenges individual institutions may encounter.

While we recognize the myriad uncertainties in understanding the best evidence-based practice for the mothernewborn dyad during the postpartum period, we encourage families and clinicians to remain diligent in learning up-to-date evidence and ultimately working in partnership for the safest and best practice for all parties involved.

NANN and NPA acknowledge the potential trauma and exacerbation of postpartum mental health issues that may negatively impact the fourth trimester.

We encourage healthcare providers to assist the mother to recognize the ideal versus realistic scenarios, acknowledge the uncertainty and grief over changing expectations, and consider higher-touch care in the weeks following delivery.

\section{Discussion}

NANN and NPA have reviewed the recommendations from the American Academy of Pediatrics (AAP) ${ }^{1}$, Centers for Disease Control and Prevention (CDC) ${ }^{2}$, and the World Health Organization (WHO) ${ }^{3}$ regarding mothernewborn infant postpartum care in the hospital if a mother is COVID-19+. All statements support and emphasize the importance of a shared-decision model between mother and the healthcare provider team to determine the need for postpartum separation of the mother-newborn dyad while they are in the hospital. 


\section{What Is Known}

- Empirical evidence to date has not shown vertical transmission of the virus through the placenta, amniotic fluid, or breastmilk. ${ }^{4-9}$

- Mortality rates for neonates specific for COVID-19 are minimal. Seven reports from China, 4,-7;10-12 one multicenter report from Italy, ${ }^{13}$ and one multicenter report from New York City ${ }^{14}$ have published data on pregnant women who are COVID-19+ delivering newborns during this pandemic. A total of 127 neonates born to mothers who are COVID-19+ were reviewed from the nine published studies. One preterm infant death was noted. ${ }^{12}$ However, this preterm neonate did not test positive for COVID-19 on day of life. ${ }^{9}$ No other fatalities were reported.

\section{Challenges}

- Small sample sizes and mother-infant separation practices varied between the institutions.

- Vertical transmission cannot yet be ruled out.

- Horizontal transmission from mother to newborn may occur, thereby increasing exposure risk to additional clinicians caring for the newborn.

- Limited resources. Necessary resources such as personnel, physical space, personal protective equipment (PPE), and medical technologies - including additional isolettes - must be available to safely care for the emergent medical needs of mother-baby dyads.

New data emerge daily.

NANN and NPA encourage perinatal care providers to engage in candid conversations with pregnant parents prior to delivery regarding risks, benefits, limitations, and realistic expectations.

We appreciate WHO's recommendation to keep mother-newborn dyads together and emphasize using good respiratory and hand hygiene at all times.

We support this recommendation so long as it is a shared decision between mother and clinical team, which includes all affected care providers (e.g., nursing, obstetric, and pediatric clinicians), and is feasible for the institution at that time.

We affirm the importance of neonatal attachment during the first days of life as discussed by $\mathrm{WHO}^{3}$ and recognize the unknown risk of exposure to the COVID-19 virus as expressed by $A A P^{1}$ and CDC. ${ }^{2}$

Another important consideration is that these mother-infant dyads are discharged from postpartum care to a same home environment. Therefore, we recommend clinicians and researchers working with this population to collect data throughout the entire neonatal period and publish timely reports to help us further understand longitudinal outcomes of neonates exposed to COVID-19, which will help inform and guide the evidence for postpartum care during this pandemic and future pandemics. 


\section{References}

1. Puopolo, K.M, Hudak, M. L., Kimberlin, D.W., \& Cummings, J. (Apr 2, 2020). Initial guidance: Management of infants born to mothers with COVID-19. Retrieved from American Academy of Pediatrics website: https://downloads.aap.org/AAP/PDF/COVID\%2019\%20Initial\%20Newborn\%20Guidance.pdf

2. U.S. Department of Health and Human Services, Centers for Disease Control and Prevention. (April 4, 2020). Considerations for inpatient obstetric healthcare settings. Retrieved from https://www.cdc.gov/coronavirus/2019-ncov/hcp/inpatient-obstetric-healthcare-guidance.html

3. World Health Organization. (April 22, 2020). What matters to women in the postnatal period? Retrieved from https://www.who.int/news-room/detail/22-04-2020-what-matters-to-women-in-the-postnatalperiod

4. Zeng, L., Xia, S., Yuan, W., Yan, K., Xiao, F., Shao, J., \& Zhou W. (2020). Neonatal early-onset infection with SARS-CoV-2 in 33 neonates born to mothers with COVID-19 in Wuhan, China. JAMA Pediatrics. Advance online publication. doi: 10.1001/jamapediatrics.2020.0878

5. Wang, X., Zhou, Z., Zhang, J., Zhu, F., Tang, Y., \& Shen, X. (2020). A case of 2019 Novel Coronavirus in a pregnant woman with preterm delivery. Clinical Infectious Diseases. Advance online publication. doi: $10.1093 / \mathrm{cid} / \mathrm{ciaa} 200$

6. Chen, H., Guo, J., Wang, C., Luo, F., Yu, X., Zhang, W., ... Zhang Y. (2020). Clinical characteristics and intrauterine vertical transmission potential of COVID-19 infection in nine pregnant women: A retrospective review of medical records. The Lancet, 395, 809-815. doi: 10.1016/S0140-6736(20)30360-3

7. Liu, W., Wang, Q., Zhang, Q., Chen, L., Chen, J., Zhang, B., ... Sun, Z. (2020). Coronavirus disease 2019 (COVID-19) during pregnancy: A case series. Preprints, 2020020373. Advance online publication.

8. Di Mascio, D., Khalil, A., Saccone, G., Rizzo, G., Buca, D., Liberati, M., ... D'Antonio, F. (2020). Outcome of Coronavirus spectrum infections (SARS, MERS, COVID 1-19) during pregnancy: A systematic review and meta-analysis. American Journal of Obstetrics \& Gynecology MFM. Advance online publication. doi: 10.1016/i.ajogmf.2020.100107

9. Schwartz, D. A. (2020). An analysis of 38 pregnant women with COVID-19, their newborn infants, and maternal-fetal transmission of SARS-CoV-2: Maternal coronavirus infections and pregnancy outcomes. Archives of Pathology \& Laboratory Medicine. Advance online publication. doi: 10.5858/arpa.2020-0901$\underline{\text { SA }}$

10. Zhang, L., Jiang, Y., Wei, M., Cheng, B. H., Zhou, X. C., Li, J., ... Hu, R. H. (2020). Analysis of the pregnancy outcomes in pregnant women with COVID-19 in Hubei Province. Zhonghua Fu Chan Ke Za Zhi, 55, E009. Advance online publication. doi: 10.3760/cma.j.cn112141-20200218-00111 
11. Liu, D., Li, L., Wu, X., Zheng, D., Wang, J, Yang, L., \& Zheng, C. (2020). Pregnancy and perinatal outcomes of women with coronavirus disease (COVID-19) pneumonia: A preliminary analysis. AJR. American Journal of Roentgenology. Advance online publication. doi: 10.2214/AJR.20.23072

12. Zhu, H., Wang, L., Fang, C., Peng, S., Zhang, L., Chang, G., Xia, S., \& Zhou, W. Clinical analysis of 10 neonates born to mothers with 2019-nCoV pneumonia. Translational Pediatrics, 9(1), 51-60. link

13. Ferrazzi, E., Frigerio, L., Savasi, V., Vergani, P., Prefumo, F., Barresi, S., ... Cetin, I. (2020). Mode of delivery and clinical findings in COVID-19 infected pregnant women in Northern Italy. Retrieved from https://papers.ssrn.com/sol3/papers.cfm?abstract id $=3562464$

14. Breslin, N., Baptiste, C., Gyamfi-Bannerman, C., Miller, R., Martinez, R., Bernstein, K., ... Goffman, D. (2020). COVID-19 infection among asymptomatic and symptomatic pregnant women: Two weeks of confirmed presentations to an affiliated pair of New York City hospitals. American Journal of Obstetrics \& Gynecology MFM. Advance online publication. doi: 10.1016/j.ajogmf.2020.100118

\section{Resources:}

\section{www.nationalperinatal.org/NPAandNANN}

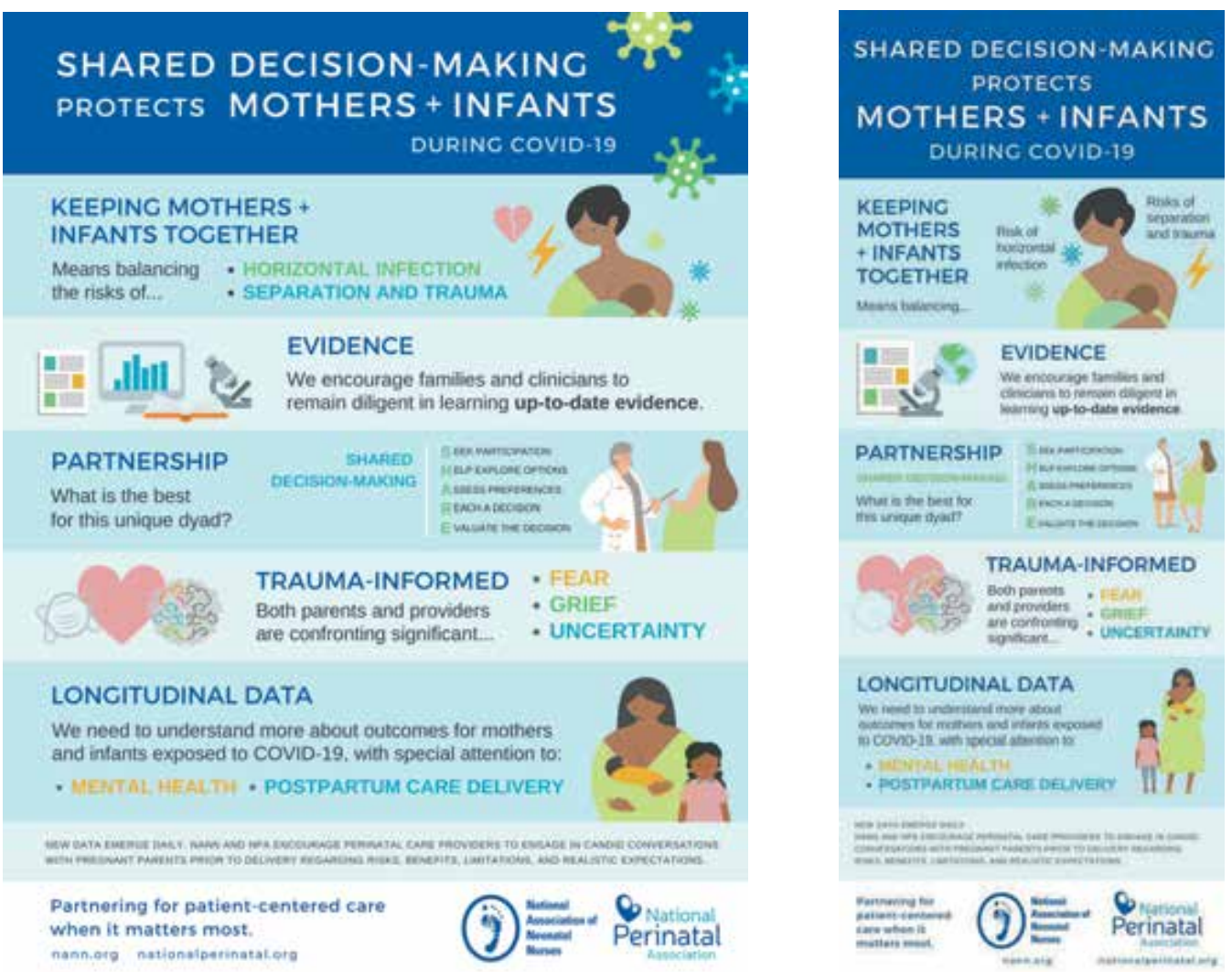



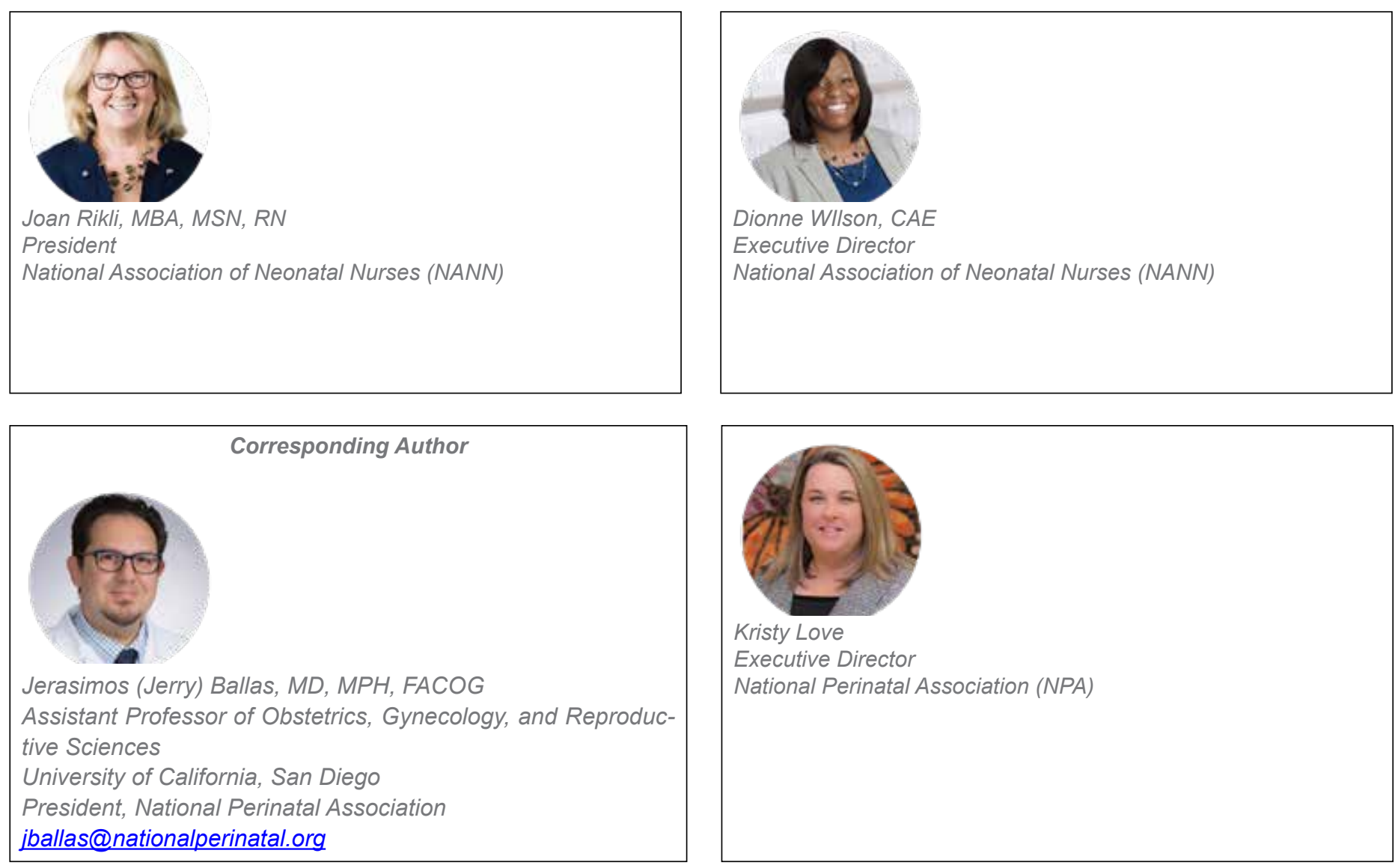

\section{NATIONAL PERINATAL ASSOCIATION \\ CORONAVIRUS}

\section{RELIABLE RESOURCES:}

- CDC: 2019 Novel Coronavirus

- The Lancet: CoviD-19 and pregnancy

- MotherToBaby: Coronaviruses

- WHO: Emerging respiratory viruses STAY INFORMED.

ONational Perinatal
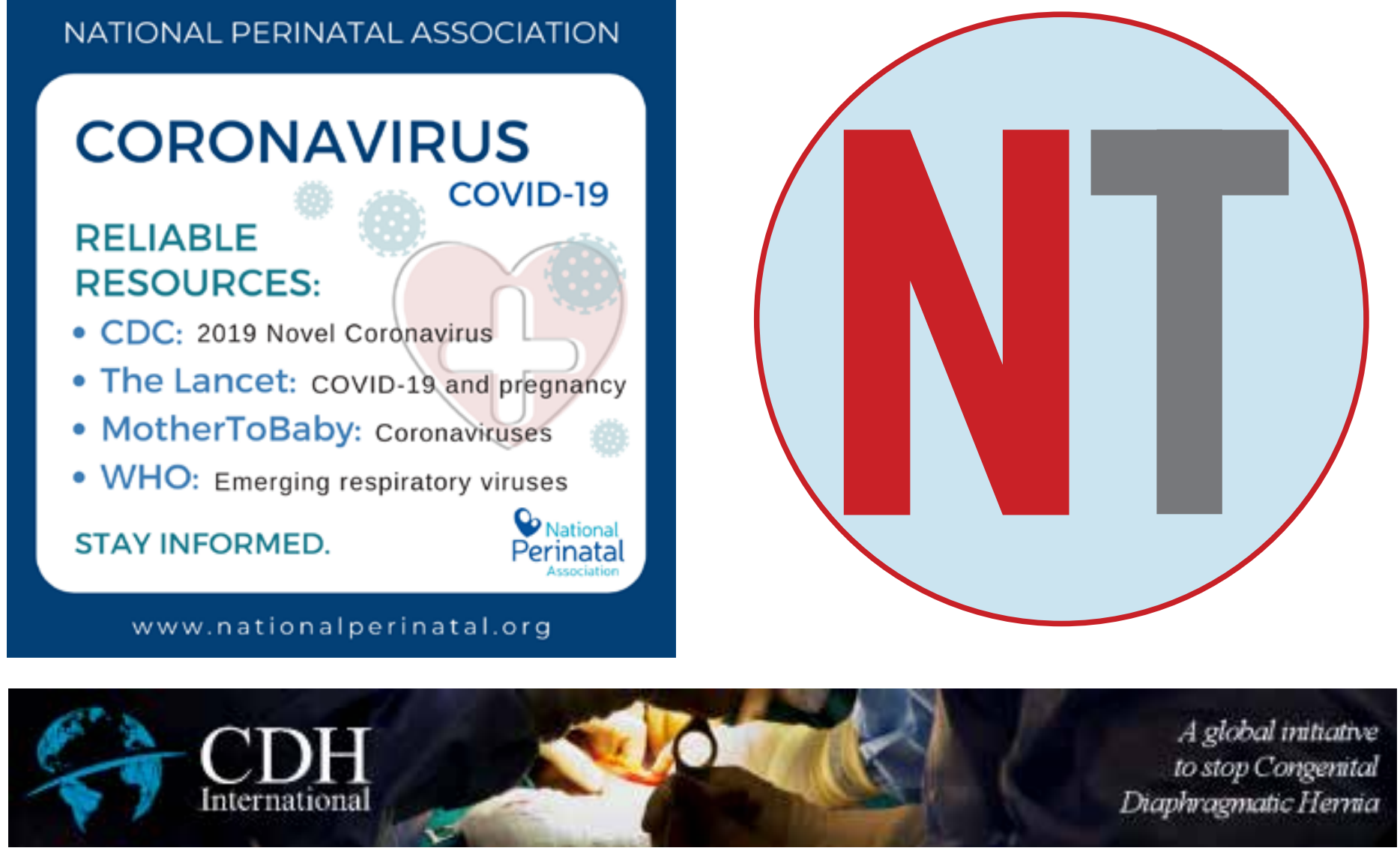